\title{
TO COMPARE ANALGESIC ACTIVITY OF INTRATHECAL CLONIDINE AND FENTANYL WITH HYPERBARIC BUPIVACAINE IN PATIENTS OF ANORECTAL SURGERY
}

\author{
Bharat Bhushan Yadav1, Vinayak Mishra², Jaishri Bogra 3 , Archana Agarwal', Sudheer Rai ${ }^{5}$, Abhishek Prakash 6
}

${ }^{1}$ Associate Professor, Department of Anaesthesiology, Hind Institute of Medical Sciences, Sitapur, Uttar Pradesh, India.

${ }^{2}$ Assistant Professor, Department of Surgery, Hind Institute of Medical Sciences, Sitapur, Uttar Pradesh, India.

3Professor, Department of Anaesthesiology, Hind Institute of Medical Sciences, Sitapur, Uttar Pradesh, India.

${ }^{4}$ Professor, Department of Anaesthesiology, Hind Institute of Medical Sciences, Barabanki, Uttar Pradesh, India.

${ }_{5}^{5}$ Assistant Professor, Department of Anaesthesiology, Hind Institute of Medical Sciences, Sitapur, Uttar Pradesh, India.

${ }^{6}$ Associate Professor, Department of Anaesthesiology, Hind Institute of Medical Sciences, Sitapur, Uttar Pradesh, India.

\begin{tabular}{l}
\hline ABSTRACT \\
BACKGROUND \\
There are various adjuvants used along with bupivacaine but clonidine and fentanyl both prolong sensory and motor block and \\
duration of analgesia. In this study we aim to evaluate the onset and duration of sensory and motor block, post-operative analgesia, \\
and adverse effects of clonidine and fentanyl as an adjuvant with hyperbaric bupivacaine in patients of anorectal surgery.
\end{tabular}

\section{METHODS}

This prospective randomized controlled trial was performed among 60 patients of either sex, aged 18-60 years who belonged to ASA I to III. Group I (BF) received $0.5 \%$ hyperbaric bupivacaine $(0.5 \mathrm{ml})$ and fentanyl $(15 \mu \mathrm{g})$ and Group II (BC) received $0.5 \%$ hyperbaric bupivacaine $(0.5 \mathrm{ml})$ and clonidine $(30 \mu \mathrm{g})$. The onset and duration of sensory and motor block, post-operative analgesia, VAS score, hemodynamic parameters, sedation and adverse effects were recorded and analysed.

\section{RESULTS}

The onset of sensory block was comparable in group BF (8.83 \pm 1.62$)$ and group BC (8.16 \pm 1.37$)$. The onset of motor block was faster in group $\mathrm{BC}(8.90 \pm 1.24)$ as compared to group BF $(9.70 \pm 1.66)$. The mean time for 2 segment regression, duration of sensory block and duration of motor block were significantly lower $(<0.001)$ in group BC as compared to group BF.

\section{CONCLUSIONS}

Low-dose of intrathecal clonidine as an adjuvant to hyperbaric bupivacaine provided prolonged duration of sensory block and postoperative analgesia with more sedation as compared to intrathecal fentanyl.

\section{KEY WORDS}

Analgesia, Bupivacaine, Clonidine, Fentanyl, Postoperative

HOW TO CITE THIS ARTICLE: Yadav BB, Mishra V, Bogra J, et al. To compare analgesic activity of intrathecal clonidine and fentanyl with hyperbaric bupivacaine in patients of anorectal surgery. J. Evolution Med. Dent. Sci. 2019;8(29):2336-2340, DOI: $10.14260 /$ jemds/2019/512

\section{BACKGROUND}

Extensive advancement in ambulatory procedures requires changes in the clinical anaesthesia practice. The social and economic pressures have changed and so have views of surgeons and anaesthesiologists. About $60 \%$ to $70 \%$ of all elective procedures are currently performed in outpatient settings in the United States and some European countries.[1,2] Now a days, spinal anaesthesia may not be used for such procedures due to extended lower limb motor block.[3] So, anaesthesiologists must become familiar with techniques allowing fast spinal block recovery. Studies with low hypobaric bupivacaine doses have shown that this technique helps fast recovery. ${ }^{[4,5]}$ However, low spinal anaesthesia doses depend on individual response and some patients may not obtain adequate anaesthesia.

'Financial or Other Competing Interest': None.

Submission 28-05-2019, Peer Review 02-07-2019,

Acceptance 08-07-2019, Published 22-07-2019.

Corresponding Author:

Dr. Jaishri Bogra,

Professor and HOD, Department of Anaesthesiology,

Hind Institute of Medical Sciences,

Mau, Ataria, Sitapur, Uttar Pradesh, India.

E-mail: jaishrikgmu@gmail.com

DOI: $10.14260 /$ jemds $/ 2019 / 512$

\section{(c) $(7)$}

In spinal anaesthesia, hyperbaric bupivacaine is frequently used local anaesthetic. Low doses of intrathecal bupivacaine will decrease the intensity and duration of sensory and motor block; as an adjuvant clonidine and fentanyl decreases the dose of bupivacaine and improves the quality of spinal anaesthesia.[6-9]

The Intrathecal clonidine is an agonist for $\alpha 2$ adrenoceptor. It is clearly increasing the duration of sensory and motor block of spinal anaesthesia. It decreases the requirements of local anaesthetics and increase the postoperative analgesia requirement. ${ }^{[6-9]}$ The adequate dose of intrathecal clonidine $(1-2 \mu \mathrm{g} / \mathrm{kg})$ as an adjuvant to local anaesthetics was significantly increase the intensity and duration of sensory and motor blocked.[6] It is associated with sedation, bradycardia and relative hypotension. The low-dose intrathecal clonidine showed effectiveness with no systemic side effects. $[7,10]$

Fentanyl is a $\mu 1$ - and $\mu 2$-receptor agonist, has a more preferable drug as an adjuvant because of its fast onset, modest duration (1-4 h), and minimal delayed respiratory depression risk. The recommended effective safe dose of spinal fentanyl is 10-25 mg.[11] Previously, various studies have shown that low dose of fentanyl as an adjuvant to hyperbaric bupivacaine increases the sensory blockade and duration with low intensity of the motor blockade.[12,13] In 
present study, we have used a low dose of intrathecal clonidine (30 micro gm) and fentanyl as an adjuvant to establish its efficacy. The aim of this study to identify whether and low dose of intrathecal bupivacaine in combination with $15 \mu \mathrm{g}$ fentanyl and $30 \mu \mathrm{g}$ clonidine would provide adequate anaesthesia for anorectal surgery without increasing side-effects or delaying hospital discharge.

\section{METHODS}

This prospective randomized controlled trial was performed after getting approval from Ethical Committee and informed consent will be taken from all the patients. This study was performed in 60 patients of either sex, aged 18-60 years with belonged to American Society of Anaesthesiology (ASA) grade I to III. None of the patients had any contraindication for spinal anaesthesia. Patients scheduled for elective anorectal surgery will be enrolled in the study.

On the basis of previous study, difference in the mean duration of onset of sensory block $(\mu 1-\mu 2)$ was 0.95 in treatment group 1 (5.93) and group 2 (6.88) and the average population variance $(\sigma 2) 1.14 .{ }^{[14]}$ The sample size $(n)=2(\mathrm{Z} \alpha / 2$ $\left.+\mathrm{Z}_{[1-\beta]}\right)^{2} \times \sigma^{2} /(\mu 1-\mu 2)^{2}$, assuming $80 \%$ power and 0.05 level significance, was 22 in each group. Considering any dropouts, we had enrolled 30 patients in each group. Patients were randomized into two groups using computer generated random number table-

- Group I (BF)-0.5\% Hyperbaric bupivacaine (0.5 ml) and fentanyl $(15 \mu \mathrm{g})$

- Group II (BC)-0.5\% Hyperbaric bupivacaine $(0.5 \mathrm{ml})$ and clonidine $(30 \mu \mathrm{g})$

All patients were premedicated with oral midazolam (7.5 mg) 2 hours preoperatively. Ringer's lactate hydration solution $(15 \mathrm{ml} / \mathrm{kg})$, a midline spinal puncture will be performed by using a 26-gauge Quincke spinal needle using a 26-gauge Quincke spinal needle at L4/L5. The L4/5 interspace was identified by all patients had spinal anaesthesia according to a line between the upper borders of the iliac crest. Tachycardia and bradycardia have been defined as heart rate $>100 / \mathrm{min}$ and $<60 / \mathrm{min}$. respectively. The level of sensory blockade was assessed bilaterally by pin prick method along midclavicular line. The time to achieve the peak level of sensory block and time to reach maximum block height for regression of two segments were noted. Motor blockade was assessed by using modified Bromage scale (0: no motor block; 1: inability to raise extended legs; 2 : inability to flex knees; 3 : inability to flex ankle and foot).[7] Duration of anaesthesia was measured as the time interval from intrathecal injection to regression of the sensory block below L1. The time for first analgesic requirement for the first time following spinal anaesthesia was noted. The 10-point visual analog scale (VAS) score was used to assess the pain hourly for 24 hours. Rescue analgesia was given with i.v. tramadol $50 \mathrm{mg}$. Sedation was measured hourly for 24 hours on a four-point scale (Grade 0 , awake and alert; 1, mildly sedated, easily aroused; 2, moderately sedated, aroused by shaking; 3, deeply sedated, difficult to be aroused by physical stimulation).[15]

Intraoperative complications was treated as follows: hypotension ( $<90 \mathrm{mmHg}$ systolic blood pressure) was treated with increments of $5 \mathrm{mg}$ ephedrine, bradycardia $(<50 \mathrm{bpm}$ heart rate) was treated with $0.3 \mathrm{mg}$ of atropine, and oxygen desaturation (pulse oximetry oxygen saturation $<90 \%$ on room air) was treated with oxygen via Hudson's face mask. If a patient complained about discomfort or pain, midazolam $0.05 \mathrm{mg} / \mathrm{kg}$ and fentanyl $25 \mu \mathrm{g}$ IV will be administered by the anaesthesiologist in incremental doses. Adverse events (hypotension, bradycardia, nausea, vomiting, sedation, shivering and pruritus) will be recorded during operation and recovery.

\section{Statistical Methods}

Statistical analysis was performed by using SPSS software 15. Sensory and motor block characteristics were compared using the student's t-test. The demographic data and proportion of side effects were compared using the chi-square test $\left(\chi^{2}\right)$ and statistical significance was observed at $\mathrm{p}<0.05$.

\section{RESULTS}

The demographic profile included age, gender, height, weight, ASA grade and duration of surgery were comparable in both groups as shown in table 1 . The mean age of the patients in group $\mathrm{BF}$ and group $\mathrm{BC}$ were $43.90 \pm 8.06$ and $45.03 \pm 7.54$ years, respectively. In group $\mathrm{BF}$ and $\mathrm{BC}, 76.67 \%$ and $83.33 \%$ males were present. The mean height of patients were $164.97 \pm 6.91$ and $166.47 \pm 7.05(\mathrm{~cm})$ in group BF and BC, respectively. The mean weight of patients in group $\mathrm{BF}$ and group BC were $65.70 \pm 6.60$ and $64.57 \pm 7.13(\mathrm{~kg})$, respectively. Total $60.0 \%$ and $76.67 \%$ patients have ASA grade I and $40.0 \%$ and $23.33 \%$ patients have ASA grade II in group BF and group $\mathrm{BC}$, respectively. The mean duration of surgery were $74.10 \pm 13.98$ and $75.43 \pm 12.87$ in group BF and group BC, respectively.

The onset of sensory block was $8.83 \pm 1.62$ and $8.16 \pm 1.37$ in group BF and group BC, respectively. The difference in onset of sensory block among the groups was comparable in both groups. Whereas the onset of motor block was $9.70 \pm 1.66$ and $8.90 \pm 1.24$ in group BF and group BC, respectively. The difference in onset of motor block among the groups was faster in group BC as compared to group BF. The mean time for 2 segment regression, duration of sensory block and duration of motor block were significantly lower $(<0.001)$ in group $\mathrm{BC}$ as compared to group BF. The first-time analgesia requirement was significantly higher in group BC with mean $257.00 \pm 28.67$ min as compared to group BF with mean $350.17 \pm 32.66 \mathrm{~min}$ as shown in Table 2.

The visual analog scale score (VAS) at $2 \mathrm{hrs}$ and at the at first time rescue analgesic requirement are shown in Table 3. Vas score at first time rescue analgesic requirement was comparable in both group $\mathrm{BF}$ and group $\mathrm{BC}$.

The mean heart rate of patients was shown in Fig. 1. The mean heart rate was $83.07 \pm 5.87$ and $82.12 \pm 6.72$ beats $/ \mathrm{min}$ in group $\mathrm{A}$ at baseline $(0 \mathrm{~min})$. The baseline heart rate was comparable in both group BF and group BC (Fig. 1).

The mean atrial blood pressure (MAP) of patients was shown in Fig. 2. The mean MAP was $98.5 \pm 10.01$ and $97.0 \pm 9.52$ beats/min in group BF and group BC at baseline 0 min, respectively. The baseline heart rate was comparable in both group BF and group BC (Fig. 2).

The hemodynamic parameters (heart rate and MAP) are shown in Fig. 1 and Fig. 2. The heart rate and MAP did not show any significant change in both group $\mathrm{BF}$ and group $\mathrm{BC}$, intraoperative. 


\begin{tabular}{|c|c|c|c|}
\hline Demographic Variables & Group BF & Group BC & p-Value \\
\hline Age (Years) Mean \pm SD & $43.90 \pm 8.06$ & $45.03 \pm 7.54$ & 0.576 \\
\hline Sex & & & \\
Male & $23(76.67 \%)$ & $25(83.33 \%)$ & 0.527 \\
Female & $7(23.33)$ & $5(16.67 \%)$ & \\
\hline Height (cm) & $164.97 \pm 6.91$ & $166.47 \pm 7.05$ & 0.409 \\
\hline Weight (kg) & $65.70 \pm 6.60$ & $64.57 \pm 7.13$ & 0.526 \\
\hline ASA Grade & $18(60.00 \%)$ & $23(76.67 \%)$ & 0.171 \\
I & $12(40.00 \%)$ & $7(23.33)$ & 0.647 \\
II & $74.10 \pm 13.98$ & $75.43 \pm 12.87$ & \\
\hline \multicolumn{3}{|c|}{ Table 1. Patients Characteristics } \\
\hline \multicolumn{2}{|c|}{ Data are represented as mean, \pm SD, and n (\%). SD=Standard deviation } \\
\hline
\end{tabular}

\begin{tabular}{|c|c|c|c|}
\hline Parameters & Group BF & Group BC & p-Value \\
\hline Onset of Sensory Block & $8.83 \pm 1.62$ & $8.16 \pm 1.37$ & 0.90 \\
\hline Time for 2 Segment Regression & $78.50 \pm 8.58$ & $130.77 \pm 15.09$ & $<0.001^{*}$ \\
\hline Duration of Sensory Block & $143.77 \pm 13.77$ & $179.17 \pm 12.74$ & $<0.001^{*}$ \\
\hline Onset of Motor Block & $9.70 \pm 1.66$ & $8.90 \pm 1.24$ & $0.039^{*}$ \\
\hline Duration of Motor Block & $158.53 \pm 18.78$ & $195.13 \pm 14.49$ & $<0.001^{*}$ \\
\hline First Time Analgesia requirement & $257.00 \pm 28.67$ & $350.17 \pm 32.66$ & $<0.001^{*}$ \\
\hline \multicolumn{4}{|l|}{ Table 2. Characteristics of Sensory and Motor Block } \\
\hline
\end{tabular}

\begin{tabular}{|c|c|c|c|}
\hline Variable & Group BF & Group BC & p-Value \\
\hline VAS score (2 hrs.) & 0.0 & 0.0 & - \\
\hline VAS score (At first time rescue analgesic) & $2.90 \pm 1.06$ & $2.80 \pm 0.96$ & 0.704 \\
\hline \multicolumn{3}{|c|}{ Table 3. Pain Score } \\
\hline
\end{tabular}

\begin{tabular}{|c|c|c|c|}
\hline & Group BF & Group BC & p-Value \\
\hline Hypotension & $4(13.33 \%)$ & $3(10.00 \%)$ & 0.694 \\
\hline Headache & $2(6.67 \%)$ & $0(0.00 \%)$ & 0.155 \\
\hline Bradycardia & $3(10.0 \%)$ & $1(3.33 \%)$ & 0.309 \\
\hline Nausea & $2(6.67)$ & $0(0.00 \%)$ & 0.155 \\
\hline Vomiting & $1(3.33)$ & $0(0.00 \%)$ & 0.321 \\
\hline Itching & $4(13.33)$ & $0(0.00 \%)$ & $0.039^{*}$ \\
\hline Shivering & $2(6.67)$ & $0(0.00 \%)$ & 0.155 \\
\hline Respiratory Depression & $0(0.00 \%)$ & $0(0.00 \%)$ & - \\
\hline Sedation & $0(0.00 \%)$ & $4(13.33)$ & $0.039^{*}$ \\
\hline Dryness of mouth & $0(0.00 \%)$ & $3(10.00 \%)$ & 0.078 \\
\hline Pruritus & $8(26.67 \%$ & $0(0.00 \%)$ & $0.003^{*}$ \\
\hline \multicolumn{4}{|l|}{ Table 4. Complication } \\
\hline${ }^{*}=$ Significant $(\mathrm{p}=<0.05)$
\end{tabular}
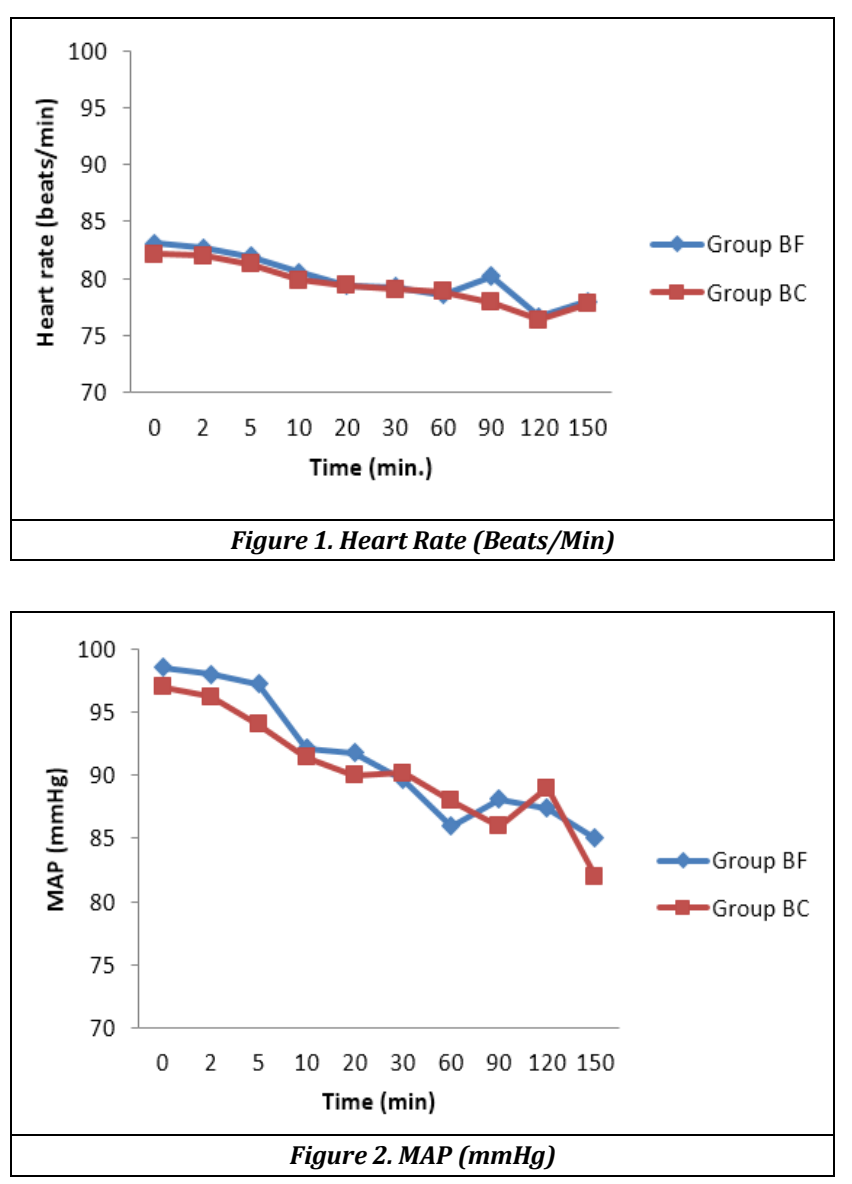

The incidence of hypotension, headache, bradycardia, nausea, vomiting, shivering, respiratory depression and dryness of mouth were comparable in both group BF and group $\mathrm{BC}$ as shown in Table 4. Itching and pruritus were significantly more in group $\mathrm{BF}$ as compared to group $\mathrm{BC}$. The sedation was significantly greater in group $\mathrm{BC}$ as compared to Groups BF $(\mathrm{p}=0.039)$. Though, sedation never exceeded grade 2 .

\section{DISCUSSION}

In these studies, we found that the duration of sensory block and duration of motor block, time to two-segment regression and analgesia effects were significantly greater in clonidine group as compared to fentanyl group. Similarly, Chopra and Talwar, (2014) reported that patients receiving $30 \mu \mathrm{g}$ intrathecal clonidine with $0.5 \%$ hyperbaric bupivacaine had significantly greater duration of effective analgesia, duration of sensory block and duration motor block, and time to twosegment regression than those receiving $15 \mu \mathrm{g}$ fentanyl with $0.5 \%$ hyperbaric bupivacaine. ${ }^{[16]}$ Another study also reported that the clonidine $(45 \mu \mathrm{g})$ with $0.5 \%$ bupivacaine were significantly increased the duration of sensory block, motor block as compared to fentanyl $(15 \mu \mathrm{g})$, in infra-umbilical surgery. [17] Our results are supported by similar findings of previous study, in which the duration of sensory and motor block was significantly prolonged in group C (hyperbaric bupivacaine and $50 \mu \mathrm{g}$ clonidine) compared to Group $\mathrm{Fb}$ (hyperbaric bupivacaine and $25 \mu \mathrm{g}$ fentanyl) in lower limb orthopaedic surgery.[14] The very low dose of intrathecal clonidine $(15 \mu \mathrm{g})$ was increase the duration motor block.[18] Whereas, Ahmed et al. (2017) did not find any effect of clonidine $(25 \mu \mathrm{g})$ on the duration of motor block.[19]

In our study we found that the addition of clonidine to intrathecal bupivacaine was significantly more increase the post-operative analgesia effects as compared to fentanyl to intrathecal bupivacaine. This finding is supported by several studies, which reported that the small dose of intrathecal fentanyl to bupivacaine increased the postoperative analgesia effects but less than clonidine with bupivacaine groups.[19-22] The request of first time rescue analgesia was significantly longer in clonidine to bupivacaine group as compared to fentanyl.[12] The fentanyl $(12.5 \mu \mathrm{g})$ to intrathecal bupivacaine markedly increased the intraoperative anaesthesia, and significantly reduced the request for postoperative analgesia demand.[23] The addition of clonidine $(50 \mu \mathrm{g})$ to bupivacaine was significantly prolonged the time to first analgesic request. [24]

In our study the heart rate and mean atrial blood pressure of patients were comparable in both clonidine and fentanyl groups. The overall haemodynamic stability was observed in both clonidine $(30 \mu \mathrm{g})$ and fentanyl $(15 \mu \mathrm{g})$ with in bupivacaine. The findings of our study is supported by Chopra and Talwar, 2014, who found that the incidence of sedation to be the highest with bupivacaine with clonidine than bupivacaine fentanyl groups.[16] Similarly, the haemodynamic stability were observed in clonidine $(60 \mu \mathrm{g})$ and fentanyl (25 $\mu \mathrm{g}$ ) with in bupivacaine in patients undergoing caesarean section.[25] Various other studies also reported that the haemodynamic stability with use of fentanyl and clonidine.[26${ }^{28]}$ Biswas et al. (2002) and Agrawal et al. (2009) also reported that the haemodynamic stability with $12.5 \mu \mathrm{g}$ and $25 \mu \mathrm{g}$ of intrathecal fentanyl.[23,29] Chopra and Talwar, (2014) shows 
that the intrathecal clonidine $(30 \mu \mathrm{g})$ might not produce significant hemodynamic effects.[16] Ahmed et al. (2017) reported that the intrathecal clonidine and fentanyl with hyperbaric bupivacaine are produce good hemodynamic stability in total abdominal hysterectomy.[19]

In this study we found that the itching and pruritus were significantly more in fentanyl group whereas sedation was more in clonidine group. The incidence of hypotension, headache, bradycardia, nausea, vomiting, shivering, respiratory depression and dryness of mouth were comparable in both clonidine and fentanyl groups. Similarly, Routray et al. (2017) found that the more sedation in intrathecal clonidine $(50 \mu \mathrm{g})$ as adjuvant to hyperbaric bupivacaine as compare to intrathecal fentanyl $(25 \mu \mathrm{g})$. $^{[14]}$ Perioperative analgesia was prolonged by the addition of 75 $\mu \mathrm{g}$ of clonidine and $25 \mu \mathrm{g}$ fentanyl to bupivacaine, with increased side effects of nausea, vomiting and hypotension in the clonidine group. ${ }^{[26]} \mathrm{A}$ small dose of intrathecal clonidine as well as fentanyl is not usually associated with systemic side effects such as bradycardia, hypotension, or sedation. [25]

\section{CONCLUSIONS}

Low-dose of intrathecal clonidine $(30 \mu \mathrm{g})$ as an adjuvant to hyperbaric bupivacaine provided prolonged duration of sensory block and postoperative analgesia with more sedation as compared to intrathecal fentanyl $(15 \mu \mathrm{g})$. Impartially excellent analgesia with few sedations with negligible haemodynamic complication was observed with $30 \mu \mathrm{g}$ clonidine and it may be suggested.

\section{REFERENCES}

[1] Dahl V, Raeder J. Regional anaesthesia in ambulatory surgery. Curr Opin Anaesthesiol 2003;16(5):471-6.

[2] Katayama M, Laurito GM, Vieira JL. Anestesia subaracnóidea para artroscopia de joelho em regime ambulatorial. Rev Bras Anestesiol 1991;41:173-8.

[3] Vaghadia H. Spinal anaesthesia for outpatients: controversies and new techniques. Can J Anaesth 1998;45(5 Pt 2):R64-R75.

[4] Imbelloni LE, Beato L, Gouveia MA. Unilateral spinal anaesthesia with hypobaric bupivacaine. Rev Bras Anestesiol 2002;52(5):542-8.

[5] Imbelloni LE, Beato L, Gouveia MA. Low hypobaric bupivacaine doses for unilateral spinal anaesthesia. Rev Bras Anestesiol 2003;53(5):579-85.

[6] Dobrydnjov I, Axelsson K, Samarutel J, et al. Postoperative pain relief following intrathecal bupivacaine combined with intrathecal or oral clonidine. Acta Anaesthesiol Scand 2002;46(7):806-14.

[7] Liu S, Chiu AA, Neal JM, et al. Oral clonidine prolongs lidocaine spinal anaesthesia in human volunteers. Anaesthesiology 1995;82(6):1353-9.

[8] Rhee K, Kang K, Kim J, et al. Intravenous clonidine prolongs bupivacaine spinal anaesthesia. Acta Anaesthesiol Scand 2003;47(8):1001-5.

[9] Ota K, Namiki A, Iwasaki $H$, et al. Dose-related prolongation of tetracaine spinal anaesthesia by oral clonidine in humans. Anaesth Analg 1994;79(6):11215.

[10] Bonnet F, Buisson VB, Francois Y, et al. Effects of oral and subarachnoid clonidine on spinal anaesthesia with bupivacaine. Reg Anaesth 1990;15(4):211-4.
[11] De Santiago J, Santos-Yglesias J, Girón J, et al. Low-dose hypobaric spinal anaesthesia for anorectal surgery Effects of oral and subarachnoid clonidine on spinal anaesthesia with bupivacaine in Jackknife position: levobupivacaine-fentanyl compared to lidocainefentanyl. Rev Esp Anestesiol Reanim 2010;57(9):56570.

[12] Ben-David B, Solomon E, Levin H, et al. Intrathecal fentanyl with small-dose dilute bupivacaine: better anaesthesia without prolonging recovery. Anaesth Analg 1997;85(3):560-5.

[13] Choi DH, Ahn HJ, Kim MH. Bupivacaine-sparing effect of fentanyl in spinal anaesthesia for caesarean delivery. Reg Anaesth Pain Med 2000;25(3):240-5.

[14] Routray SS, Raut K, Pradhan A, et al. Comparison of intrathecal clonidine and fentanyl as adjuvant to hyperbaric bupivacaine in subarachnoid block for lower limb orthopedic surgery. Anaesth Essays Res 2017;11(3):589-93.

[15] Zoremba M, Wulf H. Spinal anaesthesia in day case surgery - old technique - new trends. Anasthesiol Intensivmed Notfallmed Schmerzther 2010;45(3):17680.

[16] Chopra P, Talwar V. Low dose intrathecal clonidine and fentanyl added to hyperbaric bupivacaine prolongs analgesia in gynecological surgery. J Anaesthesiol Clin Pharmacol 2014;30(2):233-7.

[17] Rana S, Singh SP, Asad M, et al. Comparative evaluation of the efficacy of intrathecal fentanyl, clonidine and fentanyl-clonidine combination as an adjuvant to bupivacaine for infra-umblical surgery. Journal of Case Reports 2018;8:67-71.

[18] Santos EJ, Riberio SC, Trindade DC, et al. Fentanyl versus clonidine as adjuvants to isobaric bupivacaine spinal anaesthesia for anus surgeries. Anaesthesiology 2007;107:A883.

[19] Ahmed F, Khandelwal M, Sharma A. A comparative study of the effect of clonidine, fentanyl and the combination of both as adjuvant to intrathecal bupivacaine for postoperative analgesia in total abdominal hysterectomy. J Anaesthesiol Clin Pharmacol 2017;33(1):102-6.

[20] Benhamou D, Thorin D, Brichant JF, et al. Intrathecal clonidine and fentanyl with hyperbaric bupivacaine improves analgesia during cesarean section. Anaesth Analg 1998;87(3):609-13.

[21] Bogra J, Arora N, Srivastava P. Synergistic effect of intrathecal fentanyl and bupivacaine in spinal anaesthesia for caesarean section. BMC Anaesthesiol 2005;5(1):5.

[22] Bhure A, Kalita N, Ingley P, et al. Comparative study of intrathecal hyperbaric bupivacaine with clonidine, fentanyl and midazolam for quality of anaesthesia and duration of post-operative pain relief in patients undergoing elective caesarean section. People's Journal of Scientific Research 2012;5(1):19-23.

[23] Biswas BN, Rudra A, Bose BK, et al. Intrathecal fentanyl with hyperbaric bupivacaine improves analgesia during caesarean delivery and in early post-operative period. Indian J Anaesth 2002;46(6):469-72. 
[24] Khandelwal M, Ahmed F, Garg A, et al. Transdermal nitroglycerine enhances the post-operative analgesic effect of intrathecal clonidine in abdominal hysterectomies. Indian J Anaesth 2012;56(1):79-81.

[25] Shidhaye RV, Shah BB, Joshi SS, et al. Comparison of clonidine and fentanyl as an adjuvant to intrathecal bupivacaine for spinal anaesthesia and postoperative analgesia in patients undergoing caesarian section. Sri Lankan J Anaesthesiol 2013;22(1):15-20.

[26] Bhattacharjee A, Singh NR, Singh SS, et al. A comparative study of intrathecal clonidine and fentanyl along with bupivacaine in spinal anaesthesia for caesarean section. J Med Soc 2015;29(3):145-9.
[27] Van Tuijl I, van Klei WA, van der Werff DB, et al. The effect of addition of intrathecal clonidine to hyperbaric bupivacaine on postoperative pain and morphine requirements after caesarean section: a randomized controlled trial. Br J Anaesth 2006;97(3):365-70.

[28] Bajwa SJ, Bajwa SK, Kaur J, et al. Prevention of hypotension and prolongation of postoperative analgesia in emergency cesarean sections: a randomized study with intrathecal clonidine. Int J Crit Illn Inj Sci 2012;2(2):63-9.

[29] Agrawal A, Agrawal S, Asthana V, et al. Comparison of intrathecalfentanyl and sufentanil in addition to bupivacaine for caesarean section under spinal anaesthesia. J Anaesth Clin Pharmacol 2009;25 (2):154-6. 